\title{
A phase $1 /$ II study of oxaliplatin when added to 5-fluorouracil and leucovorin and pelvic radiation in locally advanced rectal cancer: a Colorectal Clinical Oncology Group (CCOG) study
}

\author{
D Sebag-Montefiore*, , R Glynne-Jones ${ }^{2}$, S Falk ${ }^{3}$, HM Meadows ${ }^{4}$ and T Maughan ${ }^{5}$ \\ 'Cookridge Hospital, Hospital Lane, Cookridge, West Yorkshire LSI6 6QB, UK; ${ }^{2}$ Mount Vernon Hospital, Rickmansworth Road, Northwood, Middlesex \\ HA6 2RN, UK: ${ }^{3}$ Bristol Oncology Centre, Bristol Royal Infirmary, Horefield Road, Bristol BS2 8ED, UK: ${ }^{4}$ Cancer Research UK \& UCL Cancer Trials Centre, \\ Stephenson House, 158-160 North Gower Street, London NWI 2ND, UK; ${ }^{5}$ Velindre Hospital, Whitchurch, Cardiff CF4 7XL, UK
}

\begin{abstract}
The purpose of this study was to evaluate the maximum tolerated dose (MTD) and recommended dose of oxaliplatin given synchronously with 5-fluorouracil (5FU), leucovorin (LV) and preoperative pelvic radiation for primary unresectable, locally advanced, rectal cancer. Preoperative pelvic radiotherapy using a three- or four-field technique and megavoltage photons comprised $45 \mathrm{~Gy}$ given in 25 fractions, I.8 Gy per fraction, and delivered with escalating doses of oxaliplatin in combination with low-dose LV and 5FU. Chemotherapy was given synchronously with radiotherapy in weeks I and 5. Escalating doses of oxaliplatin $\left(85,130\right.$ and I50 $\mathrm{mg} \mathrm{m}^{-2}$ ) were given on days 2 and 30, followed by low-dose LV $\left(20 \mathrm{mg} \mathrm{m}^{-2}\right)$ and $5 \mathrm{FU}\left(350 \mathrm{mg} \mathrm{m}^{-2}\right)$, both given on days I-5 and $29-33$. Surgery was performed 6-10 weeks later. The MTD was determined as the dose causing more than a third of patients to have a dose-limiting toxicity (DLT). Once the MTD was reached, a further 14 patients were treated at the dose level below the MTD. In all, 32 patients received oxaliplatin at the three dose levels, median age 60 years (range 3I-79), 24 males and eight females. The MTD was reached at $150 \mathrm{mg} \mathrm{m}^{-2}$ when four out of six patients experienced DLT. Dose-limiting grade 3 or 4 diarrhoea was reported in two out of six patients at $85 \mathrm{mg} \mathrm{m}^{-2}, 5$ out of 20 at $130 \mathrm{mg} \mathrm{m}^{-2}$ and four out of 6 at $150 \mathrm{mg} \mathrm{m}^{-2}$. Grade 3 neuropathy was reported at $130 \mathrm{mg} \mathrm{m}^{-2}$ ( 1 out of 20) and at $150 \mathrm{mg} \mathrm{m}^{-2}$ (two out of six), and serious haematological toxicity was minimal; one grade 3 anaemia at $150 \mathrm{mg} \mathrm{m}^{-2}$. In all, 28 out of 32 patients completed all treatments as planned; three had radiotherapy interrupted and three a chemotherapy dose reduction. Four patients did not proceed to surgery due to the presence of metastatic disease (two), unfitness (one) or patient refusal (one). Also, 28 patients underwent surgical resection. Histopathology demonstrated histopathological complete response (pCR) 2 out of 27 (7\%), Tmic 3 out of 27 ( I l\%), pCR + Tmic 5 out of 27 (19\%), pT0-2 6 out of 27 (22\%) and histologically confirmed clear circumferential resection margins in 22 out of 27 (8I\%). Dose-limiting toxicity with oxaliplatin is $150 \mathrm{mg} \mathrm{m}^{-2}$ given days 2 and 30 when added to the described 5FU LV and 45 Gy radiation preoperatively. The acceptable toxicity and compliance at $130 \mathrm{mg} \mathrm{m}^{-2}$ recommend testing this dose in future phase II studies. The tumour downstaging and complete resection rates are encouragingly high for this very locally advanced group.

British Journal of Cancer (2005) 93, 993-998. doi:I0.1038/sj.bjc.66028I8 www.bjcancer.com
\end{abstract}

(C) 2005 Cancer Research UK

Keywords: 5-fluorouracil; oxaliplatin; locally advanced rectal cancer; preoperative chemoradiation

A curative surgical resection remains the most important component of the modern multimodality management of rectal cancer. However, randomised controlled trials (Swedish Rectal Cancer Trial, 1997; Kapiteijn et al, 2001; Sauer et al, 2004) and two meta-analyses (Cammà et al, 2000; Colorectal Cancer Collaborative Group, 2001) have also demonstrated that adjuvant radiation can reduce the rate of locoregional recurrence, although its impact on overall survival is less clear. The meta-analyses show greater benefit for preoperative radiotherapy treatment.

*Correspondence: Dr D Sebag-Montefiore; E-mail: David.Sebag-Montefiore@leedsth.nhs.uk

Received 27 July 2005; revised 19 September 2005; accepted 20 September 2005
Recent advances that have improved the outcome in rectal cancer include a more radical surgical technique incorporating mesorectal excision (Enker et al, 1995, Heald et al, 1998) and a more accurate histopathological examination of the resected specimen, reporting the proximity of microscopic tumour to the circumferential resection margin (CRM) (Quirke et al, 1986). Individual surgical series, a population-based audit (Wibe et al, 2002) and evidence from a randomised controlled trial (Nagtegaal et al, 2002), all demonstrate lower rates of local recurrence following mesorectal excision compared with the previous randomised trials that included a surgery alone arm. In addition, involvement of the CRM is associated with a significantly increased risk of local recurrence and also metastatic disease.

There is an increasing use of preoperative chemoradiation (CRT) in patients with locally advanced rectal cancer, despite the fact that there are few trials that have compared preoperative CRT 
with radiation alone (Frykholm et al, 2001; Bosset et al, 2004). The aims of treatment are to reduce the extent of the primary tumour to allow macroscopic removal to take place, treat potential microscopic disease close to or beyond the mesorectal fascia and, if present, also treat micrometastatic disease outside the radiation fields.

Most CRT schedules in current use combine pelvic radiation with either continuous infusion 5-fluorouracil (5FU) or 5FU modulated by leucovorin (LV). Mature results from the EORTC 22921 and FFCD 9203 trials of operable T3/T4 rectal cancer have recently demonstrated a convincing reduction in locoregional failure when a CRT regimen of $5 \mathrm{FU}$ and LV (as used in this study) is added to $45 \mathrm{~Gy}$ of pelvic radiation (Bosset et al, 2004, 2005; Gerard et al, 2005). Phase III trials in metastatic colorectal cancer have demonstrated statistically significant improvements in the overall response rate and progression-free survival when oxaliplatin is added to a combination of 5FU LV (de Gramont et al, 2000; Grothey, 2002; Goldberg et al, 2004). In the adjuvant setting, the addition of oxaliplatin to $5 \mathrm{FU}$ LV significantly improves diseasefree survival (DFS) (André et al, 2004). As the EORTC 22921 and FFCD 9203 trials used 5FU LV-based CRT schedules, it was a logical step to develop preoperative radiation schedules that incorporate the addition of oxaliplatin to this regimen. The choice of the 5FU LV regimen required the oxaliplatin to be given in weeks 1 and 5 to ensure concomitant administration.

Oxaliplatin is also recognised to have radiosensitising effects in both cell cultures and mouse xenografts. In preclinical models of combined radiotherapy and oxaliplatin, an 8-h oxaliplatin exposure was associated with a dose-related cell kill rate (Blackstock et al, 2002). Synergistic effects with radiation were observed when oxaliplatin was given both before and after radiation. In mouse xenograft models of colorectal cancer, tumour growth has been shown to be inhibited by combined oxaliplatin and radiation (Blackstock et al, 2000).

The present study aimed to evaluate the addition of two doses of oxaliplatin 4 weeks apart to a regimen of CRT that uses folinic acid and 5FU daily during the first and fifth weeks of pelvic radiation (45 Gy), as used in the EORTC 22921 and FFCD 9203 phase III trials (Bosset et al, 2004; Gerard et al, 2005).

\section{PATIENTS AND METHODS}

\section{Study design}

This dose escalation study aimed to increase the dose of oxaliplatin given on days 2 and 30 in successive cohorts when added to a CRT regimen consisting of low-dose LV and a short infusion of 5FU administered concurrently with radiation until the maximum tumour dose was reached. All patients received radiotherapy ( $45 \mathrm{~Gy})$ with $\mathrm{LV}\left(20 \mathrm{mg} \mathrm{m}^{-2}\right)$ and $5 \mathrm{FU}\left(350 \mathrm{mg} \mathrm{m}^{-2}\right.$ administered over $1 \mathrm{~h}$ ) on days $1-5$ and 29-33 (see Figure 1). There were four planned oxaliplatin dose levels, each consisting of six patients.
Oxaliplatin was administered in $250 \mathrm{ml}$ dextrose over $2 \mathrm{~h}$ on days 2 and $30\left(85,130,150,170 \mathrm{mg} \mathrm{m}^{-2}\right)$. Dose-limiting toxicities (DLTs) were defined to include grade III or IV diarrhoea, nausea, vomiting, thrombocytopaenia and neutropaenia according to the National Cancer Institute Canada common toxicity criteria revised 1994 definitions and grade III acute sensorimotor neuropathy (i.e. functional impairment). Toxicity was recorded prospectively weekly up to and including week 10 .

If grade III or IV DLT was observed in two or less patients in a cohort of six, then a further cohort was treated at the next dose level. The maximum tolerated dose (MTD) was defined if three or more of six patients experienced DLT. Once the MTD was defined, the preceding dose level would then be expanded and a total of 20 patients treated at the recommended dose.

The primary end points of the study were acute grade III/IV toxicity and compliance with the planned doses of chemotherapy and radiotherapy. Secondary end points included the histopathological complete response (pCR) rate, resectability rate, local recurrence rate and late morbidity.

\section{Eligibility criteria}

Eligibility criteria included histologically confirmed adenocarcinoma, WHO performance status $0-2$ and no evidence of metastatic disease using chest X-ray and abdominopelvic CT. Acceptable haematological and renal function was required: neutrophils $>1.5 \times 10^{9} 1^{-1}$, platelets $\geqslant 100 \times 10^{9} 1^{-1}$, and serum creatinine $<1.25 \times$ the institutions upper limit of normal range.

Patients with locally advanced, biopsy-proven carcinoma of the rectum were included either on the basis of fixity on digital rectal examination (DRE), T4 stage on pelvic CT or when MRI demonstrated a high risk of involvement of the CRM. The method used to define locally advanced disease, the distance of the inferior tumour border to the anal verge $(\mathrm{cm})$ and intended surgical procedure were also recorded.

Patients were excluded from the study because of prior chemotherapy or pelvic radiation, lack of efficient contraception or pregnancy, inflammatory bowel disease and cardiac conditions that would deter the safe delivery of 5FU. Patients having six episodes of stool per day or who were incontinent of faeces were also excluded.

\section{Pelvic radiation}

Using information from clinical examination and pelvic MRI, the gross tumour volume (GTV) was defined using a CT planning scan. To derive the planning target volume (PTV), margins were added to the GTV according to the radiation planning diagrams $(3 \mathrm{~cm}$ laterally, superiorly and inferiorly, $2 \mathrm{~cm}$ anteriorly) included in the protocol, with the exception of the posterior border, which was always located on the most posterior aspect of the bony sacrum. Patients were treated prone with a full bladder using either

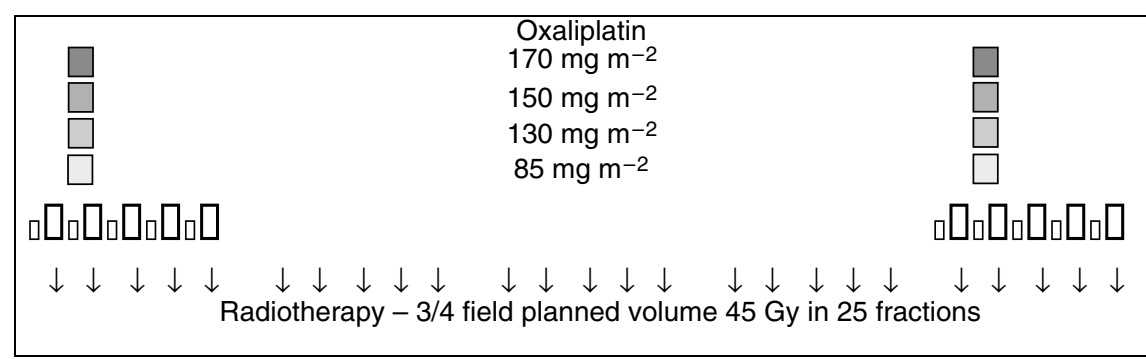

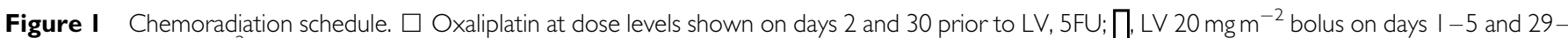
33; $\downarrow$, 5FU $350 \mathrm{mg} \mathrm{m}^{-2}$ 60-min infusion on days I-5 and 29-33; $\downarrow$, radiotherapy 1.8 Gy per fraction. 
a three- or four-field technique. A total dose of $45 \mathrm{~Gy}$ was delivered to the International Commission on Radiation Units intersection point using 25 daily fractions of $1.8 \mathrm{~Gy}$. Orthogonal film simulation was performed with opacification of the small bowel using barium sulphate $300 \mathrm{ml}$ with gastrograffin $20 \mathrm{ml}$.

\section{Surgery and histopathology}

Surgery was recommended to take place 6-10 weeks after completion of CRT. Histopathological examination of the resected specimen was performed according to the technique described by Quirke (Birbeck and Quirke, 1999). The CRM is considered involved if microscopic tumour is present at or less than $1 \mathrm{~mm}$ from the circumferential or radial resection margin.

\section{Assessment during and after treatment}

Full blood count, urea creatinine and electrolytes, and liver function tests and acute toxicity scores were assessed prospectively on weeks 1-6 and 10. On completion of CRT, follow-up appointments were given at 3,6 12, 24 and 36 months to assess tumour recurrence and late toxicity.

For the purposes of this study, local recurrence has been defined in patients who have had a complete macroscopic resection as evidence of either an intraluminal or extraluminal mass below the sacral promontory and biopsy-proven adenocarcinoma, or CEA abnormal with or without the presence of metastases. Radiological evidence of interval enlargement of the mass (minimum interval of 6 weeks) was required if based on CT scans alone (biopsy negative and CEA normal).

\section{RESULTS}

Between February 1999 and October 2001, a total of 32 patients were recruited from four centres: 24 males, eight females, median age 60 years (range 31-79). Their tumour characteristics are summarised in Table 1. Five patients were excluded from the prospective assessment of DLT and dose recommendations. Two patients failed to start treatment, two patients refused the day 30 dose of oxaliplatin, but had not experienced DLT, and one patient died during CRT of an intestinal perforation considered unrelated to study therapy.

\section{Protocol compliance}

During the dose escalation phase, full compliance was achieved (no reduction in planned dose or duration of treatment) for radiation dose or chemotherapy dose at $85 \mathrm{mg} \mathrm{m}^{-2}$, whereas one out of six patients at $130 \mathrm{mg} \mathrm{m}^{-2}$ required interruption of radiation and three out of six patients at $150 \mathrm{mg} \mathrm{m}^{-2}$ required chemotherapy dose reduction (two of which also had radiotherapy interrupted).

Table I Patient and tumour characteristics

\begin{tabular}{ll}
\hline Characteristic & \multicolumn{1}{c}{$\mathbf{n = 3 2}$} \\
\hline Median age (range) & $60(31-79)$ \\
Male:female & $24: 8$ \\
WHO status $0: 1: 2$ & $9: 21: 2$ \\
Site of tumour & \\
Upper:mid: lower & $4: 12: 16$ \\
Local extent & \\
Fixed/unresectable & 16 \\
Locally advanced on MRI & 16 \\
\hline
\end{tabular}

$\mathrm{WHO}=$ World Health Organisation; $\mathrm{MRI}=$ magnetic resonance imaging.
The median field size, in all patients, for the posterior/anterior field was $15.1 \mathrm{~cm}$ (range $10.5-20.1$ ) height $\times 13.9 \mathrm{~cm}$ (range $11.4-$ 18.0 ) width, and for the lateral/oblique fields $15.4 \mathrm{~cm}$ (range $11.5-$ 20.0 ) height $\times 13.4 \mathrm{~cm}$ (range 10.5-20.5) width. In all, 28 out of 32 patients proceeded to have radical surgery; the median time to surgery was 9 weeks (interquartile range 8-11 weeks). Information on pathological status was available on 27 patients due to the loss of one surgical specimen.

\section{Acute toxicity}

The acute grade III/IV toxicity experienced is summarised for the three dose levels and the subsequent patients treated in the expanded cohort at $130 \mathrm{mg} \mathrm{m}^{-2}$ in Table 2. During the dose escalation phase, DLT was seen in two out of six patients at $85 \mathrm{mg} \mathrm{m}^{-2}$ and in four out of six patients at $150 \mathrm{mg} \mathrm{m}^{-2}$. In view of the toxicity seen at $150 \mathrm{mg} \mathrm{m}^{-2}$, the decision was made to stop recruitment to this dose level and to expand the $130 \mathrm{mg} \mathrm{m}^{-2}$ dose level to the planned total of 20 patients.

The most common toxicity was diarrhoea; this occurred in 10 patients, eight grade 3 and two grade 4 . Three patients had grade 3 neurotoxicity, 15 others reported this toxicity at grade 1 or 2 , all of these events resolved within 4weeks following treatment. Haematological toxicity was rare, with only one grade 3 anaemia reported at the $150 \mathrm{mg} \mathrm{m}^{-2}$ dose level.

\section{Response to treatment}

Tumour downstaging was defined by comparing clinical TN stage prior to treatment (as determined by pelvic MRI) with histopathological stage post surgery. Chemoradiation achieved downstaging in 8 out of $27(30 \%)$ of patients. The pathological stages at surgery were $\mathrm{T} 0 \mathrm{~N} 0=2, \quad \mathrm{~T} 1 \mathrm{NO}=1, \quad \mathrm{~T} 0 \mathrm{~N} 1=1, \quad \mathrm{~T} 1 \mathrm{~N} 1=1, \quad \mathrm{~T} 2 \mathrm{~N} 0=3$, $\mathrm{T} 3 \mathrm{~N} 0=9, \mathrm{~T} 3 \mathrm{~N} 1=6, \mathrm{~T} 3 \mathrm{NX}=1$ and $\mathrm{T} 4 \mathrm{~N} 0=3$. It can be seen that CRT achieved a complete pathological response in 2 out of $27(7 \%)$ cases who proceeded to surgery (Table 3 ) and 2 out of $32(6 \%)$ of

Table 2 Acute toxicity

\begin{tabular}{lcccc}
\hline Oxaliplatin dose $\left(\mathbf{m g ~ m}^{-\mathbf{2}}\right)$ & $\mathbf{8 5}$ & $\mathbf{1 3 \mathbf { a } ^ { \mathbf { a } }}$ & $\mathbf{1 5 0}$ & All \\
\hline No. of patients & 6 & $6 / 14$ & 6 & 32 \\
Patients with DLT & 2 & $2 / 3$ & 4 & $1 \mathrm{I}$ \\
Gd 3 diarrhoea & 2 & $0 / 3$ & 3 & 8 \\
Gd 4 diarrhoea & 0 & $2 / 0$ & 0 & 2 \\
Gd 3 neurological & 0 & $1 / 0$ & 2 & 3 \\
Gd 3 anaemia & 0 & $0 / 0$ & 1 & 1 \\
\hline
\end{tabular}

The figures in this column indicate the numbers in the initial six patients treated at this dose level, followed by the numbers in the expanded group once the MDT was determined. ${ }^{b}$ Defined as functional impairment using the Sanofi oxaliplatin neurotoxoicity score.

Table 3 Pathological response

\begin{tabular}{lcccc}
\hline Oxaliplatin dose $\mathbf{(} \mathbf{m g ~ m}^{-\mathbf{2}} \mathbf{)}$ & $\mathbf{8 5}$ & $\mathbf{1 3 0}$ & $\mathbf{1 5 0}$ & All (\%) \\
\hline Number of patients & 6 & 20 & 6 & 32 \\
Number operated & 6 & $19^{\mathrm{a}}$ & $3^{\mathrm{b}}$ & 28 \\
PCR & $0 / 6$ & $2 / 19$ & $0 / 2$ & $2 / 27(7 \%)$ \\
PTO-2 pNO & $2 / 6$ & $6 / 19$ & $0 / 2$ & $8 / 27(30 \%)$ \\
Tmic & $1 / 6$ & $2 / 19$ & $0 / 2$ & $3 / 27(11 \%)$ \\
-ve CRMc & $5 / 6$ & $15 / 19$ & $2 / 2$ & $22 / 27(81 \%)$ \\
\hline
\end{tabular}

${ }^{\mathrm{a} O n e}$ patient inoperable. ${ }^{\mathrm{b}}$ One inoperable, one unfit for surgery, one patient refused, one specimen lost. ${ }^{c}$-ve $C R M=$ tumour clearance of more than $1 \mathrm{~mm}$ from circumferential resection margin, $\mathrm{PCR}=$ histopathological complete response; Tmic = microscopic disease only detected in surgical specimen; CRM = circumferential resection margin. 
the whole group. Histopathology also demonstrated microscopic disease only (Tmic) in 3 out of 27 (11\%), patients, pCR + Tmic in 5 out of $27(19 \%)$, pT0 -2 in 6 out of $27(22 \%)$ and histologically confirmed $(>1 \mathrm{~mm})$ clear CRM in 22 out of $27(81 \%)$.

\section{Surgery}

Of the 32 evaluable patients, four did not proceed to surgery due to the presence of metastatic disease (two), patient refusal (one) and unfitness for surgery (one) (Figure 2). All patients had a preliminary clinical assessment by their surgeon at entry, and were categorised on the basis of height of the cancer from the anal verge as requiring an abdominoperineal resection (APR) or anterior resection (AR). Of the 28 surgical procedures, 15 had an APR, two of which had initially been assessed as requiring an AR, the remaining 13 had APR as expected (one with cystectomy). Ten patients had an AR, six of which had been anticipated and four that had been expected to require an APR. One patient had a Hartman's procedure after an initial assessment of an APR. Two additional patients required exenterative surgery (one initially assessed to require this procedure and one initially assessed as requiring $A R)$. There were no unexpected post operative complications or deaths.

\section{Local recurrence and survival}

The strength of this study is that the median follow-up is 41 months (range 6-64 months) for all patients and 41 months for surviving patients (range 31-64 months). In all, 23 of the 32 patients remain alive at the time of writing. Of the 22 patients having complete surgical clearance of tumour (CRM-ve) six relapsed (one local, four distant, and one at local and distant sites), of which four subsequently died of disease (Figure 2 and Table 4). Of the five incomplete resections (CRM + ve) only one patient is alive without disease ( 45 months from the start of treatment); the remaining four progressed: one local, one distant, and two local and distant, both of whom died. Three of the four patients who were not resected died and the fourth patient is alive at 45 months with a pelvic mass. The DFS for the whole group at 3 years is $62 \%$ (95\% CI $43-77 \%$ ) (see Figure 3) and $82 \%$ (95\% CI 58-93\%) for those having had a complete resection. All six patients who had T0-2 NO tumours remain alive and disease free. Of the 21 patients with $\mathrm{T} 3 / 4 \mathrm{NO} / 1$ or $\mathrm{T} 0-2 \mathrm{~N} 1$ disease, 11 are alive and disease free, four are alive with disease and six have died due to disease.

\section{Late effects}

Severe late effects were uncommon, despite the combination of oxaliplatin and radiotherapy. Grade 3 late toxicity was reported in five patients $\left(85 \mathrm{mg} \mathrm{m}^{-2}\right.$; one diarrhoea, $130 \mathrm{mg} \mathrm{m}^{-2}$; one tenesmus and diarrhoea, $150 \mathrm{mg} \mathrm{m}^{-2}$; one tenesmus and one bleeding and pain). As four of the five patients had relapsed disease, it is unclear whether the symptoms reflect radiation or recurrence.

\section{DISCUSSION}

The objective of this study was to determine the MTD of oxaliplatin in combination with pelvic radiotherapy and low-dose folinic acid and a 60-min infusion of $5 \mathrm{FU}$ with $45 \mathrm{~Gy}$ of

Table 4 Pattern of recurrence following radical resection

\begin{tabular}{lcccc}
\hline Oxaliplatin dose $\mathbf{(} \mathbf{m} \mathbf{~ m ~}^{-\mathbf{2}} \mathbf{)}$ & $\mathbf{8 5}$ & $\mathbf{1 3 0}$ & $\mathbf{1 5 0}$ & All \\
\hline Number of patients & 6 & 19 & 3 & 28 \\
Any disease & 3 & 7 & 1 & $11 / 27(41 \%)$ \\
Local recurrence & 1 & 3 & 0 & $4 / 27(15 \%)$ \\
Distant metastases & 3 & 5 & 1 & $9 / 27(33 \%)$ \\
Death & 3 & 3 & 1 & $7 / 27(26 \%)$ \\
\hline
\end{tabular}

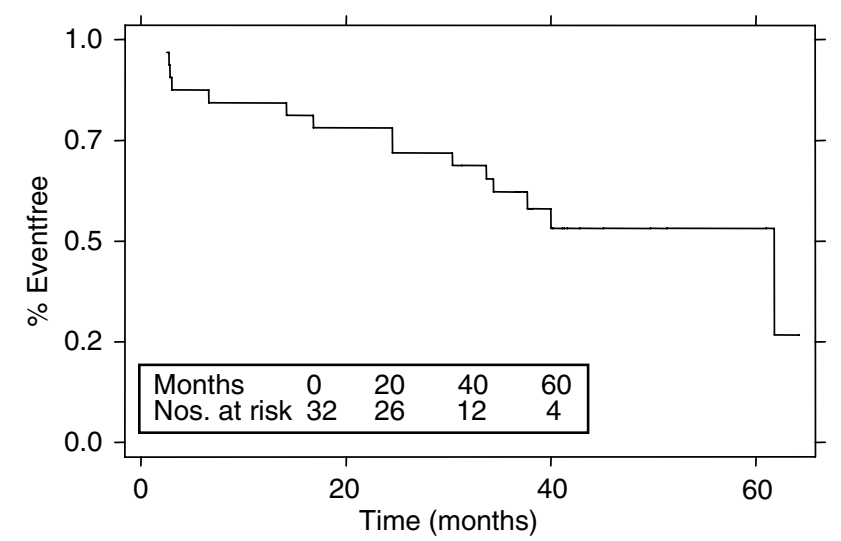

Figure 3 Disease-free survival - all patients.

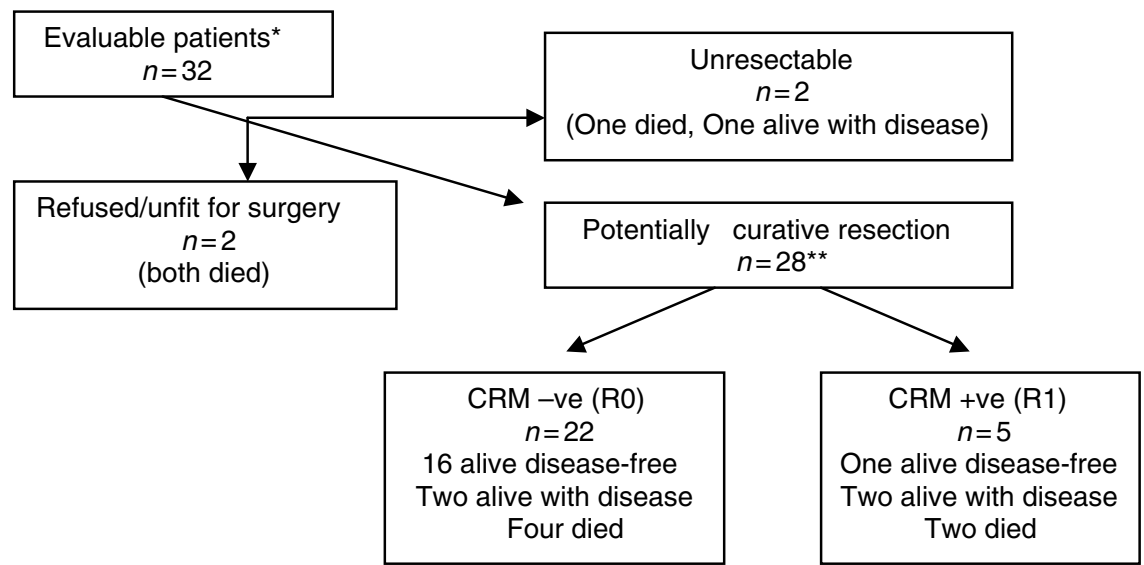

Figure 2 Patient outcome. *Five unassessable patients not included; one died, two did not start treatment, two refused week 5 chemo; *** one specimen lost. 
radiotherapy given preoperatively in patients with locally advanced rectal cancer. The eligibility criteria used in this study define a relatively homogeneous group of very locally advanced rectal cancer. The MTD of oxaliplatin combined with pelvic radiotherapy (using relatively large field size) has been defined as $150 \mathrm{mg} \mathrm{m}^{-2}$ on days 2 and 30 , and the recommended dose as $130 \mathrm{mg} \mathrm{m}^{-2}$. The dose intensity of oxaliplatin $\left(260 \mathrm{mg} \mathrm{m}^{-2}\right.$ over 5 weeks) in the present study is similar to that achieved by Freyer et al (2001) using a day 1 and 29 schedule and higher than that used $\left(200 \mathrm{mg} \mathrm{m}^{-2}\right)$ in a recent German study (Rödel et al, 2003).

The histologically confirmed RO (CRM - ve) resection rate of $81 \%$ is high for this locally advanced group (Bosset et al, 2005; Gerard et al, 2005). In this study, only two patients had unresectable disease and only three patients had partial pelvic clearances. In contrast, the German CAO/ARO/AIO - 94 study (Rödel et al, 2003) reported 8 out of 31 patients who underwent exenteration or resection of adjacent organs.

This study did not seek to assess the impact or control the use of postoperative chemotherapy. Only $7 \%$ of the study group received such treatment and this consisted of 5FU LV. The EORTC 22921 trial (Bosset et al, 2005) did not demonstrate a significant impact on outcome when postoperative chemotherapy was compared with no further treatment when given after preoperative CRT, and it is unlikely that the use of postoperative chemotherapy will have significantly altered the outcome of this study.

Enthusiasm for preoperative CRT in the management of rectal cancer is increasing. The German CAO/ARO/AIO - 94 study protocol has convincingly shown improved locoregional control and reductions in acute and late toxicity with preoperative CRT (Sauer et al, 2004) vs postoperative combined modality treatment for stage II/III resectable rectal cancer. The rationale for preoperative CRT is attractive, as it combines early systemic chemotherapy treatment simultaneously with a locoregional treatment.

In addition, over the past decade, nonrandomised studies have confirmed that preoperative treatment with radiotherapy (Wagman et al, 1998) can facilitate sphincter-sparing options. A study from Lyon compared immediate and delayed surgery after preoperative radiotherapy (Francois et al, 1999). Sphincter preservation was achieved in $79 \%$ of patients with a long interval (4-6 weeks) following radiotherapy, compared with $69 \%$ of patients where the interval was only short ( 2 weeks). A further report (Glehen et al, 2003) documents that, with a median followup of 6.3 years, no differences were found in the degree of local control, overall survival, morbidity, anal function or surgical complications between the two groups. The addition of chemotherapy to radiotherapy can be used to shrink the primary tumour further and facilitate sphincter-sparing options. Impressive results appear to have been achieved in phase II studies with CRT (Grann et al, 1997; Rullier et al, 2001) and long-term followup has confirmed an excellent outcome if there is marked shrinkage of the primary tumour (Ruo et al, 2002).

There have been several reported phase I and II studies integrating oxaliplatin into fluoropyrimidine-based CRT schedules (Gérard et al, 2003; Gambacorta et al, 2004; Aschele et al, 2005). There are, however, important differences between these and the current study. Gambacorta et al (2004) evaluated the combination of raltitrexed and oxaliplatin with $50.4 \mathrm{~Gy}$ radiation. Aschele et al (2005) used a weekly schedule of oxaliplatin combined with continuous infusion 5FU and $50.4 \mathrm{~Gy}$ irradiation. Gérard et al (2003) used the same doses of 5FU/LV as this study, but delivered this as a continuous infusion over $24 \mathrm{~h}$ for days $1-5$ and 29-33, but did not determine the MTD of the combination of oxaliplatin on days 1 and 29 when added to 5FU/LV and radiation.

The present study has a number of important differences from the above studies. Firstly, the total dose of radiation was fixed at $45 \mathrm{~Gy}$, a total dose that is $10 \%$ lower than the other studies. This dose might be expected to be associated with a lower incidence of late complications. Secondly, this study formally determined the MTD and recommended dose of oxaliplatin when added to a validated CRT fluoropyrimidine schedule used in two recent phase III trials (Bosset et al, 2005; Gerard et al, 2005). Finally, this study reports outcome data that is relatively mature (41-month median follow-up) and is also based on the circumferential margin status. We are not aware that any other combination CRT study has reported such data. This is superior to retrospective data with 5FU CRT (Sebag-Montefiore et al, 2005). Now that there is clear evidence that locoregional control is improved by the addition of the $5 \mathrm{FU} / \mathrm{LV}$ regimen used in this study to $45 \mathrm{~Gy}$ of pelvic radiation, there is a strong rationale for future trials to establish the benefit of the addition of oxaliplatin.

Further studies by our group, including the CORE study (DSM personal communication) abstract submitted to ECCO and Socrates studies (Gerard et al, 2005; Glynne-Jones et al, 2003, 2005), will further clarify the potential of using oxaliplatin in combination with oral fluoropyrimidines and radiotherapy in locally advanced rectal cancer. These data suggest that combination radiochemotherapy leads to improved early histopathological outcome measures. This has the potential to translate into improved long-term outcomes in rectal cancer, both in terms of quality of life and overall survival, and will be tested in current and future phase III trials.

In conclusion, the MTD with oxaliplatin is confirmed as $150 \mathrm{mg} \mathrm{m}^{-2}$ given on days 2 and 30 , when added to the described 5FU LV and $45 \mathrm{~Gy}$ radiation preoperatively. The recommended dose of oxaliplatin in this setting is $130 \mathrm{mg} \mathrm{m}^{-2}$. This dose is associated with high compliance and manageable acute toxicity, and appears to offer significant shrinkage and pathological downstaging even for bulky T3/T4 cancers considered unresectable. In the adjuvant setting, the addition of oxaliplatin to $5 \mathrm{FU} / \mathrm{LV}$ significantly improves DFS (André et al, 2004) and may reduce the incidence of micrometastases. There are no concerns regarding excess late morbidity from this combination, and we therefore recommend testing this dose in future phase II/III studies.

\section{ACKNOWLEDGEMENTS}

We would like to thank Kathryn McRae and Sara Okumu-Fransche for data management. We would also like to acknowledge the contribution of the contributing surgeons and research nurses at the contributing institutions. This work was supported by an unrestricted educational grant from Sanofi Aventis, UK.

\section{REFERENCES}

André T, Boni C, Mounedji-Boudiaf L, Navarro M, Tabernero J, Hickish T, Topham C, Zaninelli M, Clingan P, Bridgewater J, Tabah-Fisch I, de Gramont A (2004) Multicenter International Study of Oxaliplatin/5Fluorouracil/Leucovorin in the Adjuvant treatment of Colon Cancer (MOSAIC) Investigators. $N$ Engl J Med 350: 2343-2351

Aschele C, Friso ML, Pucciarelli S, Lonardi S, Sartor L, Fabris G, Urso DL, Del Bianco P, Sotti G, Lise M, Monfardini S (2005) A phase I-II study of weekly oxaliplatin, 5-fluorouracil continuous infusion and preoperative radiotherapy in locally advanced rectal cancer. Ann Oncol 16: 1140-1146 Birbeck KF, Quirke P (1999) Reporting protocols in colorectal cancer. CPD Bull Cell Pathol 1: 58-64

Blackstock A, Tepper J, Hess S (2000) Oxaliplatin: in vitro and in vivo evidence of its radiation sensitizing activity. Int J Rad Oncol Biol Phys 46: $92-94$ 
Blackstock AW, Tepper JE, Case LD, Anderson J, Hess S (2002) In vitro and in vivo radiosensitization of colon cancer cells by cis-[(1R2R)-1,2cyclohexanediamine- $N, N^{\prime}$ ] [oxalato(2-)-O, $O^{\prime}$ ] platinum (oxaliplatin). Int $J$ Mol Med 10(Suppl 1): S68

Bosset JF, Calais G, Daban A, Berger C, Radosevic-Jelic L, Maingon P, Bardet E, Pierart M, Briffaux A (2004) Preoperative chemoradiotherapy versus preoperative radiotherapy in rectal cancer patients: assessment of acute toxicity and treatment compliance. Report of the 22921 randomised trial conducted by the EORTC Radiotherapy Group. Eur J Cancer 40: 219-224

Bosset JF, Calais G, Mineur L, Maingon P, Radosevic-Jelic L, Daban A, Bardet E, Beny A, Ollier A, Collette L (2005) Preoperative radiation (Preop RT) in rectal cancer: effect and timing of additional chemotherapy (CT) 5-year results of the EORTC 22921 trial. Proc Am Soc Clin Oncol 23: 2473 (abstract no. 3505)

Cammà C, Giunta M, Fiorica F, Pagliaro L, Craxì A, Cottone M (2000) Preoperative radiotherapy for resectable rectal cancer: a meta-analysis. JAMA 284: 1008 - 1015

Colorectal Cancer Collaborative Group (2001) Adjuvant radiotherapy for rectal cancer: a systematic overview of 8507 patients from 22 randomised trials. Lancet 358: $1291-1304$

de Gramont A, Figer A, Seymour M, Homerin M, Hmissi A, Cassidy J, Boni C, Cortes-Funes H, Cervantes A, Freyer G, Papamichael D, Le Bail N, Louvet C, Hendler D, de Braud F, Wilson C, Morvan F, Bonetti A (2000) Leucovorin and fluorouracil with or without oxaliplatin as first-line treatment in advanced colorectal cancer. J Clin Oncol 18: 2938-2947

Enker WE, Thaler HT, Cranor ML, Polyak T (1995) Total mesorectal excision in the operative treatment of carcinoma of the rectum. J Am Coll Surg 181: $335-346$

Francois Y, Nemoz CJ, Baulieux J, Vignal J, Grandjean JP, Partensky C, Souquet JC, Adeleine P, Gerard JP (1999) Influence of the interval between preoperative radiation therapy and surgery on downstaging and on the rate of sphincter-sparing surgery for rectal cancer: the Lyon R9001 randomized trial. J Clin Oncol 17: 2396

Freyer G, Bossard N, Romestaing P, Mornex F, Chapet O, Trillet-Lenoir V, Gérard JP (2001) Addition of oxaliplatin to continuous fluorouracil, Lfolinic acid, and concomitant radiotherapy in rectal cancer: the Lyon $\mathrm{R}$ 97-03 phase I trial. J Clin Oncol 19: 2433-2438

Frykholm GJ, Pahlman L, Glimelius B (2001) Combined chemo- and radiotherapy $v s$. radiotherapy alone in the treatment of primary, nonresectable adenocarcinoma of the rectum. Int J Radiat Oncol Biol Phys 50: $427-434$

Gambacorta MA, Valentini V, Coco C, Morganti AG, Smaniotto D, Micciche F, Mantini G, Barbaro B, Garcia-Vargas JE, Magistrelli P, Picciocchi A, Cellini N (2004) Chemoradiation with raltitrexed and oxaliplatin in preoperative treatment of stage II-III resectable rectal cancer: phase I and II studies. Int J Radiat Oncol Biol Phys 60: 139-148

Gerard J, Bonnetain F, Conroy T, Chapet O, Bouche O, Closon-Dejardin MT, Untereiner M, Leduc B, Francois E, Bedenne L (2005) Preoperative (preop) radiotherapy (RT) +5 FU/folinic acid (FA) in T3-4 rectal cancers: results of the FFCD 9203 randomized trial. Proc Am Soc Clin Oncol 23: 2475 (abstract no. 3504)

Gérard JP, Chapet O, Nemoz C, Romestaing P, Mornex F, Coquard R, Barbet N, Atlan D, Adeleine P, Freyer G (2003) Preoperative concurrent chemoradiotherapy in locally advanced rectal cancer with high-dose radiation and oxaliplatin-containing regimen: the Lyon R0-04 phase II trial. J Clin Oncol 21: 1119-1124

Glehen O, Chapet O, Adham M, Nemoz JC, Gerard JP (2003) Long-term results of the Lyons R90-01 randomized trial of preoperative radiotherapy with delayed surgery and its effect on sphincter-saving surgery in rectal cancer. Br J Surg 90: 996-998, doi: 10.1002/bjs.4162

Glynne-Jones R, Sebag-Montifiore D, McDonald A, Falk S, Dorkings J, Habeshaw T, Maughan T (2003) Phase I/II study of preoperative chemoradiation and capecitabine in combination with oxaliplatin in locally advanced rectal cancer. Proc Am Soc Clin Oncol 22: 5 (abstract 1174)
Glynne-Jones R, Sebag-Montefiore D, Samuel L, Falk S, Maughan T, McDonald A (2005) Socrates phase II study results: capecitabine (CAP) combined with oxaliplatin (OX) and preoperative radiation (RT) in patients (pts) with locally advanced rectal cancer (LARC). Proc Am Soc Clin Oncol 23: 292 (abstract no. 3527)

Goldberg RM, Sargent DJ, Morton RF, Fuchs CS, Ramanathan RK, Williamson SK, Findlay BP, Pitot HC, Alberts SR (2004) A randomized controlled trial of fluorouracil plus leucovorin, irinotecan, and oxaliplatin combinations in patients with previously untreated metastatic colorectal cancer. J Clin Oncol 22: 23 - 30

Grann A, Minsky BD, Cohen AM, Saltz L, Guillem JG, Paty PB, Kelsen DP, Kemeny N, Ilson D, Bass-Loeb J (1997) Preliminary results of preoperative 5-fluorouracil, low-dose leucovorin, and concurrent radiation therapy for clinically resectable T3 rectal cancer. Dis Colon Rectum 40: $515-522$

Grothey A (2002) Phase III study of bolus 5-fluorouracil (5-FU)/folinic acid (FA) (MAYO) $v s$ weekly high-dose $24 \mathrm{~h} 5$-FU infusion/FA+oxaliplatin (OXA) (FUFOX) in advanced colorectal cancer (ACRC). Proc Am Soc Clin Oncol 21: 129a (abstract 512)

Heald RJ, Moran BJ, Ryall RD, Sexton R, MacFarlane JK (1998) Rectal cancer: the Basingstoke experience of total mesorectal excision. Arch Surg 1978-1997. Arch Surg 133: $894-899$

Kapiteijn E, Marijnen CA, Nagtegaal ID, Putter H, Steup WH, Wiggers T, Rutten HJ, Pahlman L, Glimelius B, van Krieken JH, Leer JW, van de Velde CJ, for the Dutch Colorectal Cancer Group (2001) Preoperative radiotherapy combined with total mesorectal excision for resectable rectal cancer. $N$ Engl J Med 345: 638-646

Nagtegaal ID, Marijnen CA, Kranenbarg EK, Van de Velde CJ, Van Krieken $\mathrm{JH}$, Pathology Review Committee; Cooperative Clinical Investigators (2002) Circumferential margin involvement is still an important predictor of local recurrence in rectal cancer: not 1 millimetre but 2 millimetres is the limit. Am J Surg Pathol 26: 350-357

Quirke P, Durdey P, Dixon MF, Williams NS (1986) Local recurrence of rectal adenocarcinoma due to inadequate surgical resection. Histopathological study of lateral tumour spread and surgical excision. Lancet 2: 996- 999

Rödel C, Grabenbauer GG, Papadopoulos T, Hohenberger W, Schmoll HJ, Sauer R (2003) Phase I/II trial of capecitabine oxaliplatin and radiation for rectal cancer. J Clin Oncol 21: 3098-3104

Rullier E, Goffre B, Bonnel C, Zerbib F, Caudry M, Saric J (2001) Preoperative radiochemotherapy and sphincter-saving resection for T3 carcinomas of the lower third of the rectum. Ann Surg 234: 633-640

Ruo L, Tickoo S, Klimstra DS, Minsky BD, Saltz L, Mazumdar M, Paty PB, Wong WD, Larson SM, Cohen AM, Guillem JG (2002) Long-term prognostic significance of extent of rectal cancer response to preoperative radiation and chemotherapy. Ann Surg 236: 75-81

Sauer R, Becker H, Hohenberger W, Rödel C, Wittekind C, Fietkau R, Martus P, Tschmelitsch J, Hager E, Hess CF, Karstens JH, Liersch T, Schmidberger H, Raab R, for the German Rectal Cancer Study Group (2004) Preoperative versus postoperative chemoradiotherapy for rectal cancer. N Engl J Med 351: 1731 - 1740

Sebag-Montefiore D, Hingorani M, Cooper R, Chesser P (2005) Circumferential resection margin status predicts outcome after pre-operative chemoradiation for locally advanced rectal cancer 2005 Gastrointestinal Cancers Symposium. Am Soc Clin Oncol (abstract no. 193)

Swedish Rectal Cancer Trial (1997) Improved survival with preoperative radiotherapy in resectable rectal cancer. $N$ Engl J Med 336: $980-987$

Wagman R, Minsky BD, Cohen AM, Guillem JG, Paty PP (1998) Sphincter preservation in rectal cancer with preoperative radiation therapy and coloanal anastomosis: long-term follow-up. Int J Rad Oncol Biol Phys 42: $51-57$

Wibe A, Rendedal PR, Svensson E, Norstein J, Eide TJ, Myrvold HE, Soreide O (2002) Prognostic significance of the circumferential resection margin following total mesorectal excision for rectal cancer. Br J Surg 89: 1067 